\title{
Quantifying ice damage by counting branches on damaged sugar maple trees ${ }^{1}$
}

\author{
by R.A. Lautenschlager ${ }^{2}$ and John A. Winters ${ }^{2}$
}

\begin{abstract}
We quantified the productive capacity of sugar maple crowns by counting branches (third order and epicormic) on damaged trees following the 1998 ice storm in southeastern Ontario. The covariates derived from branch counts provided greater statistical confidence, for explaining post-damage root starch and sap (volume and sweetness) production, than did crown damage estimates. When combined with predictive equations for leaf area and biomass per branch, branch counts produce estimates of foliar biomass for individual trees, regardless of the amount of damage received. Although visual estimates of crown damage seem appropriate for documenting stand-level injury, those interested in individual tree responses or comparing damage among trees should consider counting branches as a way to quantify the productive capacity of trees with or without damage.
\end{abstract}

Key words: Acer saccharum, branch counts, damage assessment, foliar biomass, ice damage, sugar maple

Nous avons évalué la capacité productive des cimes d'érable à sucre en dénombrant les branches (tertiaires et pousses adventives) sur les arbres endommagés par la tempête de verglas de 1998 dans le sud-est de l'Ontario. Les covariances dérivées du dénombrement des branches ont permis une meilleure fiabilité statistique pour expliquer la production d'amidon racinaire à la suite du traumatisme et de sève (en volume et au niveau de la teneur en sucre) que les estimés de dégâts au niveau de la cime. Le dénombrement des branches, lorsque combiné aux équations de prédiction de la surface foliaire et de la biomasse par branche, a permis de produire des estimés de la biomasse foliaire, pour chacun des arbres, sans égard au niveau de dégât encouru. Même si les estimés visuels des dégâts de cime semblaient être appropriés pour documenter les dégâts aux niveau du peuplement, les personnes intéressées par les réactions de chaque arbre ou voulant comparer les dégâts entre les arbres devraient considérer le dénombrement de branches comme étant un moyen de quantifier la capacité productive des arbres ayant subis ou non des dégâts.

Mots-clés: Acer saccharum, dénombrement de branches, évaluation des dégâts, biomasse foliaire, dégâts par le verglas, érable à sucre

\section{Introduction}

The 1998 ice storm, which caused extensive damage from Fुoutheastern Ontario to the Atlantic Ocean (Irland 1998), कaised a variety of economic and ecological questions (Laut\&nschlager and Nielsen 1999), including some related to Jesponses of trees and stands to damage. Without exception, Thajor groups examining ice damage used some form of qualitative assessment (crown loss categories) (Irland 1998, Van Dyke 1999, Boulet et al. 2000). However, we hoped to document and evaluate effects of damage and post-damage remedial treatments on sugar maple (Acer saccharum) root starch, sap (volume production and sweetness), tap hole closure, foliar nutrient levels, and increment growth (Lautenschlager and Nielsen 1999); thus, we needed quantitative assessments E of individual trees that would indicate post-damage productive Dै (photosynthetic) capacity. Although spherical densiometers, hemispherical photography, the LiCor LAI-2000 Plant Canopy

2001) have been used to quantify crown architecture and response to stress and injury, a thorough literature search and calls to experts failed to identify a quantitative approach that suited our needs. Therefore, we developed a dormant-season branch-counting system to quantify the productive capacity of individual damaged sugar maple crowns.

\footnotetext{
${ }^{1}$ Paper presented at the Ice Storm 1998 Forest Research Conference, Ottawa, October 19-22, 2000.

${ }^{2}$ Ontario Ministry of Natural Resources, Ontario Forest Research Institute, 1235 Queen Street East, Sault Ste. Marie, Ontario P6A 2E5. E-mail: r.a.lautenschlager@mnr.gov.on.ca.
}

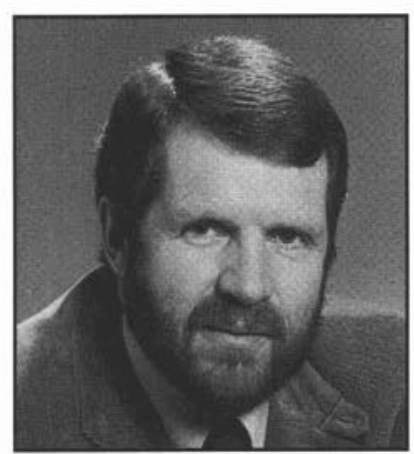

R.A. Lautenschlager

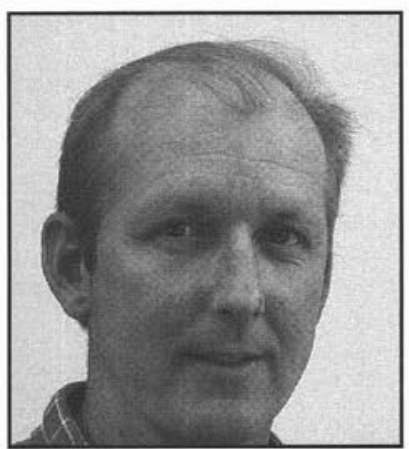

John A. Winters

\section{Methods}

During November and December 1998, a manipulative experiment (Lautenschlager and Nielsen 1999) in managed sugar bushes was established on blocks throughout southeastern Ontario, and crews of trained technicians obtained ground-based visual (qualitative) damage estimates (percentage crown loss) for individual focus trees before leaf flush. In 2000, before leaf flush (late March to early April), a single crew consisting of two technicians provided a second set of ground-based visual damage estimates for the same trees and also counted all post-damage productive third-order branches, approximately $5 \mathrm{~cm}$ and larger, remaining in all focus trees. They counted branches on focus trees (6/plot, 24/block) on 38 blocks (912 total trees) throughout the ice-damaged area (Fig. 1). During October 2000, a climber marked and counted all branches (between 2.5 and $5.0 \mathrm{~cm}$ ) on three of the focus maple trees (with a wide range of diameters) (Table 1). 


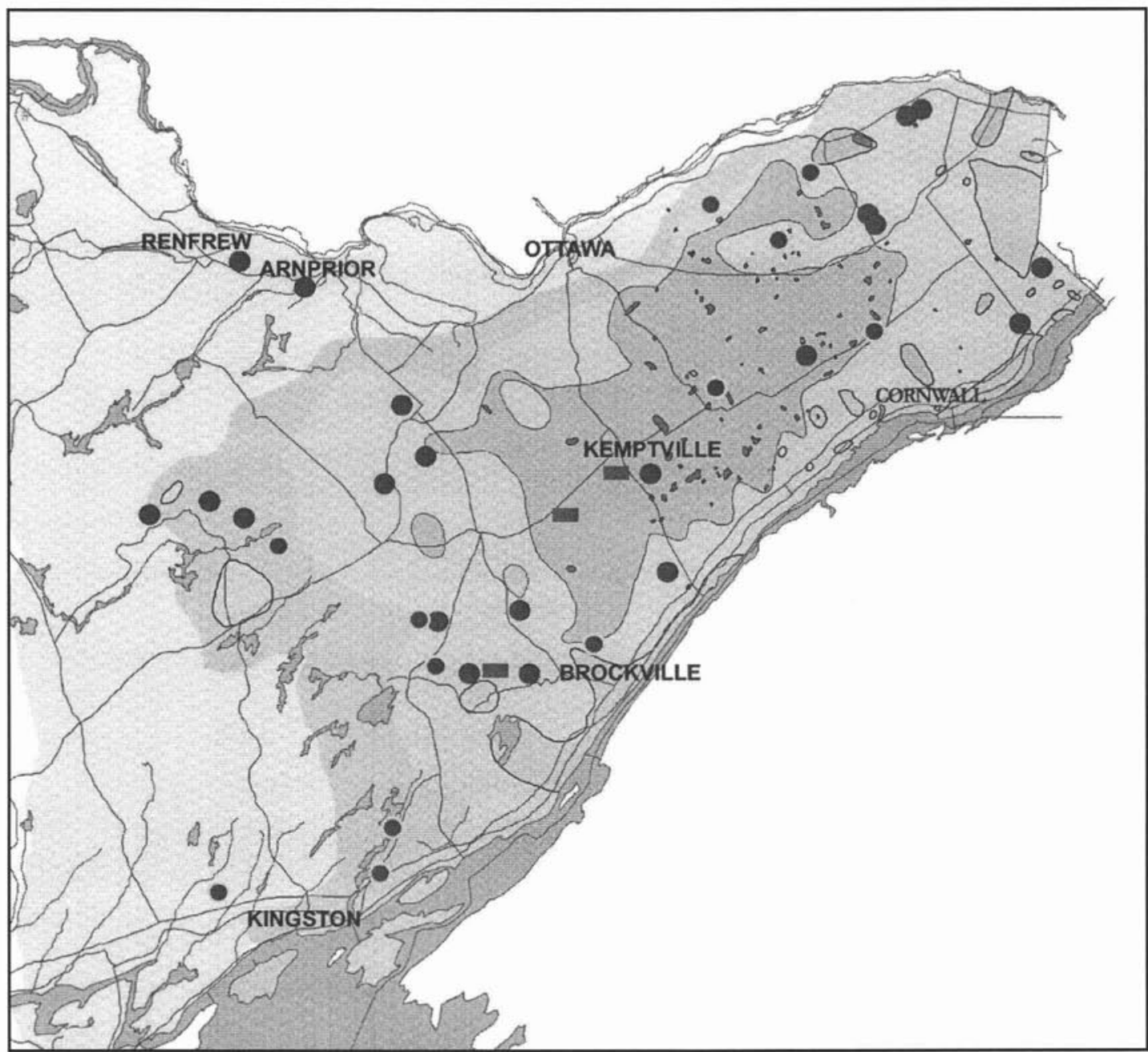

Fig. 1. Block placement (circles and rectangles) in productive sugar bushes across southeastern Ontario, superimposed on ice damage map for that area [damage severity increases with background shading - light, moderate, moderate to severe (central dark ameboid shape), severe].

Table 1. Tree-based and ground-based branch counts for individual trees with differing DBH, from a minimally damaged sugar maple stand near Kingston in southeastern Ontario

\begin{tabular}{lcccc}
\hline Tree \# & $\begin{array}{c}\text { DBH } \\
(\mathbf{C M})\end{array}$ & $\begin{array}{c}\text { Tree-based } \\
\text { count }\end{array}$ & $\begin{array}{c}\text { Ground-based } \\
\text { count }\end{array}$ & $\begin{array}{c}\text { Conversion } \\
\text { (tree/ground) }\end{array}$ \\
\hline A5 & 32.0 & 44 & 12 & 3.7 \\
B2 & 54.5 & 133 & 40 & 3.3 \\
B4 & 78.0 & 149 & 45 & 3.3 \\
& & & & Ave. $=3.4$ \\
\hline
\end{tabular}

During field training, technicians were shown which branches to count. Before field data were gathered, technicians practised on blocks with high and low damage ratings. When counting, technicians were instructed to: 1) observe and count branches independently; 2) compare their individual tree branch-counts (between counters) and determine whether they were within $10 \%$ of each other; $2 a$ ) if so, they averaged their counts; $2 b$ ) if not, they discussed reasons for differences and counted again until differences between their counts was less than $10 \%$; and 3 ) record the average.

Because counts began two years after the ice storm, epicormic branches were expected. Therefore, technicians were instructed to combine epicormic branches into groups of "branch equivalents" (Table 2) based on numbers and size of the epi- cormic branches and their related photosynthetic capacity. For instance, three clumps of epicormic branches might be judged to be equivalent to a single third-order branch (i.e., similar to the expected leaf biomass found on a normal, non-epicormic branch). In addition to counting post-damage branches and other key variables (Table 2), technicians gathered data about tapping (number of taps and type-buckets versus vacuum), crown height, and animal (insect and woodpecker) damage observed during their branch count surveys. They also took black and white photos of the individual focus trees with the highest and lowest branch count in each block (Fig. 2).

\section{Results and Discussion}

Initial (1998) individual crown damage estimates, for 864 of the 912 focus trees observed in 2000, ranged from 0 to $99 \%$ (Table 2). Comparing individual crown damage estimates gathered in 1998 and 2000 document the inexact nature of estimating crown damage (Fig. 3). Slight crown recovery seems to have occurred between 1998 and 2000; mean damage estimates, by block, for individual trees were slightly less in 2000 than 1998 on $56 \%$ of the blocks where comparative information was available (blocks 1-40) (Table 2). The average difference in individual crown damage estimates (2000-1998) was $-8.5 \pm 9.9$ (SD). Crown damage estimates were the same for $22 \%$ of trees in both years, while $80 \%$ of the estimates in 
Table 2. Means ( $N=24$ unless otherwise noted) for key variables for sugar maple stands and focus trees found on the Maple Experiment blocks in southeastern Ontario

\begin{tabular}{|c|c|c|c|c|c|c|c|c|c|c|}
\hline \multirow{2}{*}{$\frac{\text { Block \# }}{1}$} & $\begin{array}{c}\text { Soil } \\
\text { (A horizon) } \\
\text { pH }(\mathrm{N}=4)\end{array}$ & $\begin{array}{c}\text { DBH } \\
(\mathbf{C M})\end{array}$ & $\begin{array}{c}\text { Basal area } \\
\left(M^{2} / \mathrm{ha}\right) \\
(\mathrm{N}=5)\end{array}$ & $\begin{array}{c}\text { Live }^{1} \\
\text { branch } \\
\text { count }\end{array}$ & \multicolumn{2}{|c|}{$\begin{array}{l}\text { Epicormic } \\
\text { branch } \\
\text { equivalents } \\
\& \% \text { of live } \\
\text { branches }\end{array}$} & \multicolumn{2}{|c|}{$\begin{array}{c}\text { Crown }^{2} \\
\text { damage } \\
\text { rating } \\
(\% \text { damage })\end{array}$} & $\begin{array}{c}\text { Tree } \\
\text { height } \\
\text { (M) }\end{array}$ & $\begin{array}{c}\text { Live } \\
\text { crown } \\
\text { (M) }\end{array}$ \\
\hline & 5.5 & 28.0 & 14.4 & 5.3 & 1.5 & 28 & 68 & 66 & 16.1 & 6.7 \\
\hline 2 & 5.9 & 32.8 & 14.8 & 8.4 & 1.8 & 21 & 69 & 70 & 17.9 & 7.1 \\
\hline 3 & 6.6 & 32.1 & 17.2 & 9.0 & 0.7 & 7 & 41 & 42 & 23.0 & 10.0 \\
\hline 4 & 6.1 & 47.3 & 19.6 & 32.4 & 0 & 0 & 12 & 14 & 24.2 & 9.6 \\
\hline 5 & 5.6 & 40.1 & 20.8 & 19.4 & 0.2 & 1 & 10 & 11 & 22.7 & 10.9 \\
\hline 6 & 5.7 & 42.0 & 18.2 & 18.5 & 0.2 & 1 & 9 & 11 & 23.3 & 10.0 \\
\hline 7 & 5.2 & 37.2 & 21.4 & 17.8 & 0 & 0 & 34 & 39 & 21.9 & 8.1 \\
\hline 8 & 6.6 & 34.8 & 24.0 & 10.2 & 0.5 & 5 & 37 & 34 & 23.0 & 9.7 \\
\hline 9 & 6.2 & 53.7 & 19.0 & 18.3 & 1.7 & 9 & 61 & 56 & 22.3 & 12.3 \\
\hline 10 & 5.6 & 46.3 & 28.0 & 27.0 & 0.4 & 2 & 17 & 17 & 24.3 & 9.9 \\
\hline 11 & 5.4 & 41.3 & 25.2 & 10.8 & 0.3 & 3 & 61 & 47 & 24.6 & 7.9 \\
\hline 12 & 6.7 & 43.3 & 28.0 & 8.3 & 1.3 & 16 & 64 & 64 & 23.0 & 8.3 \\
\hline 13 & 6.2 & 38.5 & 19.6 & 16.2 & 0 & 0 & 51 & 50 & 23.0 & 10.6 \\
\hline 14 & 5.1 & 37.9 & 19.2 & 11.7 & 1.4 & 12 & 71 & 63 & 23.3 & 8.2 \\
\hline 15 & 5.7 & 43.5 & 16.4 & 21.7 & 0.3 & 1 & 37 & 32 & 19.5 & 12.9 \\
\hline 16 & 5.4 & 41.1 & 20.8 & 12.9 & 0.8 & 6 & 56 & 53 & 19.9 & 7.0 \\
\hline 17 & 6.5 & 38.9 & 32.8 & 20.1 & 0 & 0 & 21 & 19 & 22.0 & 9.2 \\
\hline 18 & 6.5 & 38.7 & 36.0 & 17.5 & 0 & 0 & 24 & 23 & 19.6 & 8.7 \\
\hline 19 & 6.4 & 45.5 & 20.0 & 21.1 & 0 & 0 & 10 & 9 & 23.6 & 12.2 \\
\hline 20 & 4.7 & 37.2 & 14.4 & 15.7 & 0.2 & 1 & 10 & 11 & 19.2 & 10.3 \\
\hline 21 & 6.4 & 28.6 & 17.2 & 6.5 & 0.3 & 7 & 77 & 62 & 16.9 & 7.5 \\
\hline 22 & 5.8 & 34.5 & 14.8 & 14.1 & 1.3 & 9 & 33 & 30 & 23.1 & 10.7 \\
\hline 23 & 6.0 & 45.1 & 11.6 & 19.0 & 0 & 0 & 35 & 32 & 22.8 & 11.2 \\
\hline 24 & 5.9 & 53.9 & 24.0 & 17.9 & 0.7 & 4 & 45 & 39 & 24.4 & 11.5 \\
\hline 25 & 6.1 & 40.0 & 20.0 & 20.5 & 0.4 & 2 & 28 & 28 & 21.9 & 9.5 \\
\hline 26 & 6.4 & 56.8 & 20.4 & 18.6 & 0.6 & 3 & 62 & 60 & 24.1 & 12.0 \\
\hline 27 & 6.4 & 52.7 & 21.6 & 16.3 & 0.8 & 5 & 69 & 61 & 22.4 & 11.2 \\
\hline 28 & 6.8 & 54.3 & 17.6 & 22.5 & 0.3 & 1 & 29 & 31 & 25.2 & 11.5 \\
\hline 29 & 7.1 & 57.5 & 20.0 & 14.5 & 0.9 & 6 & 35 & 36 & 25.4 & 11.1 \\
\hline 30 & 6.3 & 56.8 & 24.0 & 17.0 & 1.6 & 9 & 72 & 72 & 21.6 & 8.7 \\
\hline 31 & 4.9 & 34.5 & 23.8 & 18.3 & 0.1 & 0 & 6 & 5 & 24.5 & 8.3 \\
\hline 32 & 5.4 & 32.5 & 25.2 & 12.7 & 0.2 & 1 & 12 & 14 & 23.0 & 9.9 \\
\hline 39 & 5.9 & 43.5 & 22.8 & 16.2 & 1.1 & 7 & 39 & 39 & 24.1 & 10.7 \\
\hline 40 & 7.3 & 45.8 & 19.6 & 31.6 & 0.5 & 2 & 35 & 33 & 23.0 & 10.9 \\
\hline 41 & 6.2 & 45.4 & $?$ & 17.0 & 1.1 & 6 & $(63)^{3}$ & 49 & 25.1 & 8.3 \\
\hline 42 & 6.6 & 46.9 & 17.0 & 8.2 & 1.4 & 17 & (57) & 63 & 21.3 & 9.0 \\
\hline 43 & 5.9 & 27.9 & 18.1 & 11.0 & 1.3 & 12 & $(40)$ & 42 & 17.4 & 8.2 \\
\hline 44 & 5.6 & 45.0 & ? & 12.0 & 0.9 & 1 & $(60)$ & 58 & 20.0 & 8.0 \\
\hline
\end{tabular}

${ }^{1}$ Branch count numbers for individual trees: Min. $=0 ;$ Max. $=60 ;$ Mean=16.12 $\pm 9.43(\mathrm{SD})$.

${ }^{2}$ Damage estimates for individual trees $(\mathrm{N}=19-25 / 1998 ; \mathrm{N}=24 / 2000)$ : average absolute difference $(2000-1998)=8.44 \pm 9.93(\mathrm{SD})$; min. diff. $=0$; max. diff. $=70$; of the 2000 estimates, $22 \%$ were the same as the 1998 estimate; $80 \%$ were within \pm 10 of the 1998 estimate; $90 \%$ were within \pm 20 of the 1998 estimate; $2 \%$ were more than \pm 40 of the 1998 estimate.

${ }^{3}$ Individual tree estimates were unavailable for 1998; stand-level estimates are provided in parentheses.

2000 were within 10 percentage points of the 1998 estimate, and $90 \%$ were within 20 percentage points of the 1998 estimate. When individual trees were grouped and estimates averaged to create block-based stand-level damage estimates, the estimates were much closer between the two years (Table 2, Fig. 4).

In 2000, branches were counted on a total of 912 trees. Counts ranged from lows of zero in two heavily damaged area to highs of 60 in a lightly damaged area. Fig. 2 shows the crowns of two focus sugar maple trees examined during this study: one with many (47) and one with few (3) branches plus three coppice branch equivalents.

When compared with crown damage estimates, our branch counts have provided covariates that improve explanations of post-damage root starch, and sap (volume, and sweetness) production (T.L. Noland, Tree Biochemist, Ont. Min. Nat. Res. 2001 , pers. comm.). Branch counts are also expected to become key covariates for explaining foliar nutrient levels, tap hole closure, and growth increment following damage and remedial treatments. Branch counts, combined with predictive equations for leaf area and biomass per branch developed for sugar maple in the area (Ter-Mikaelian and Lautenschlager 2001), enable researchers to produce estimates of foliar biomass for individual focus trees, regardless of the amount of damage.

Data for the few ground-based versus tree-based branch counts show that the tree-based counter recorded approximately 3.4 branches for every branch recorded by ground-based counters (Table 1). However, ground-based branch counters were instructed to count third-order branches that were $5.0 \mathrm{~cm}$ or larger while, to better document foliar biomass, the tree-based branch counter recorded branches that were between 2.5 to $5.0 \mathrm{~cm}$ (Ter-Mikaelian and Lautenschlager 2001).

Counting branches takes extra time and adds to the cost of collecting information about ice-damaged trees. A combina- 


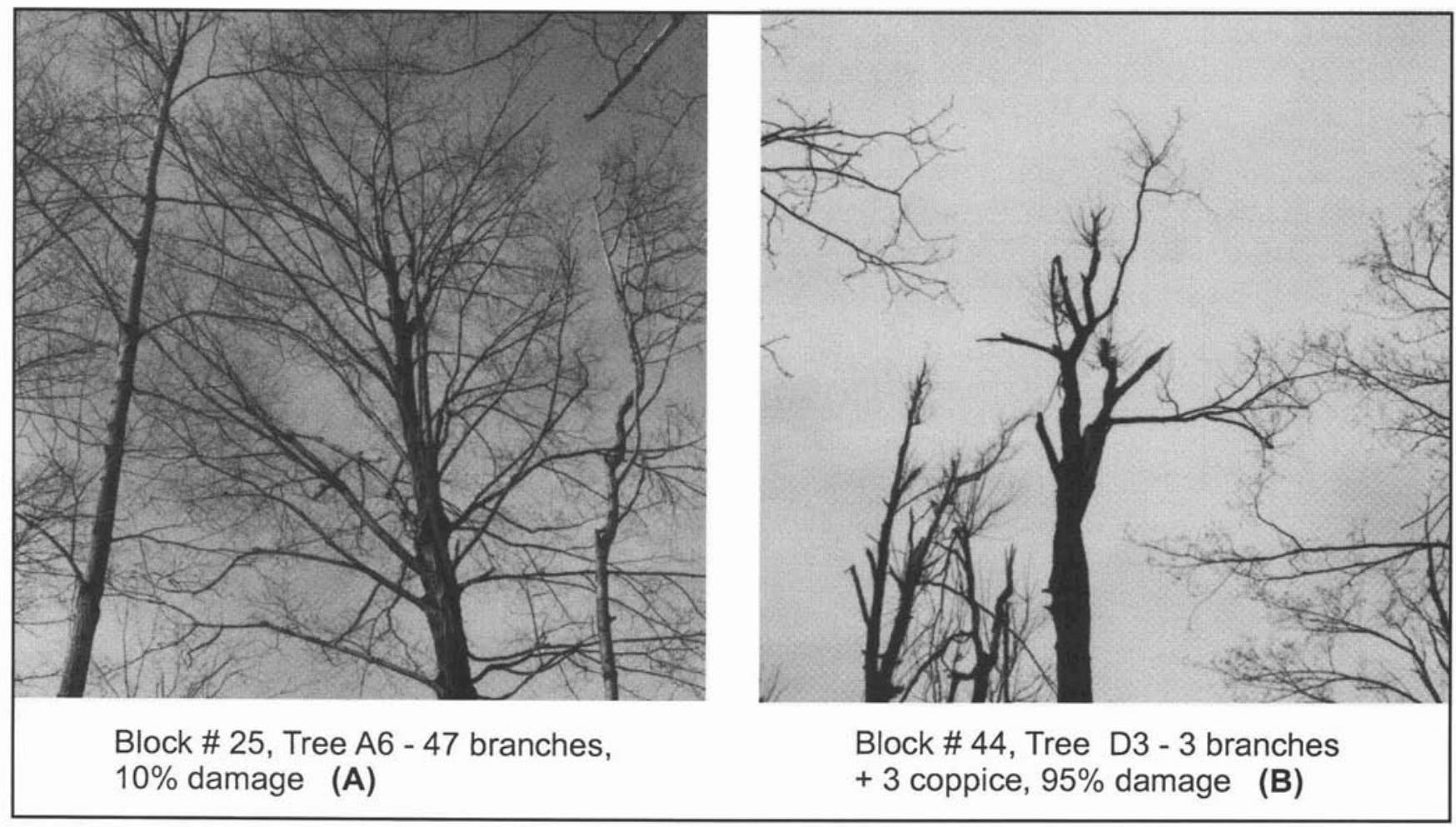

Fig. 2. Crowns of sugar maple trees with 47 remaining branches (A) and 3 remaining branches (B).

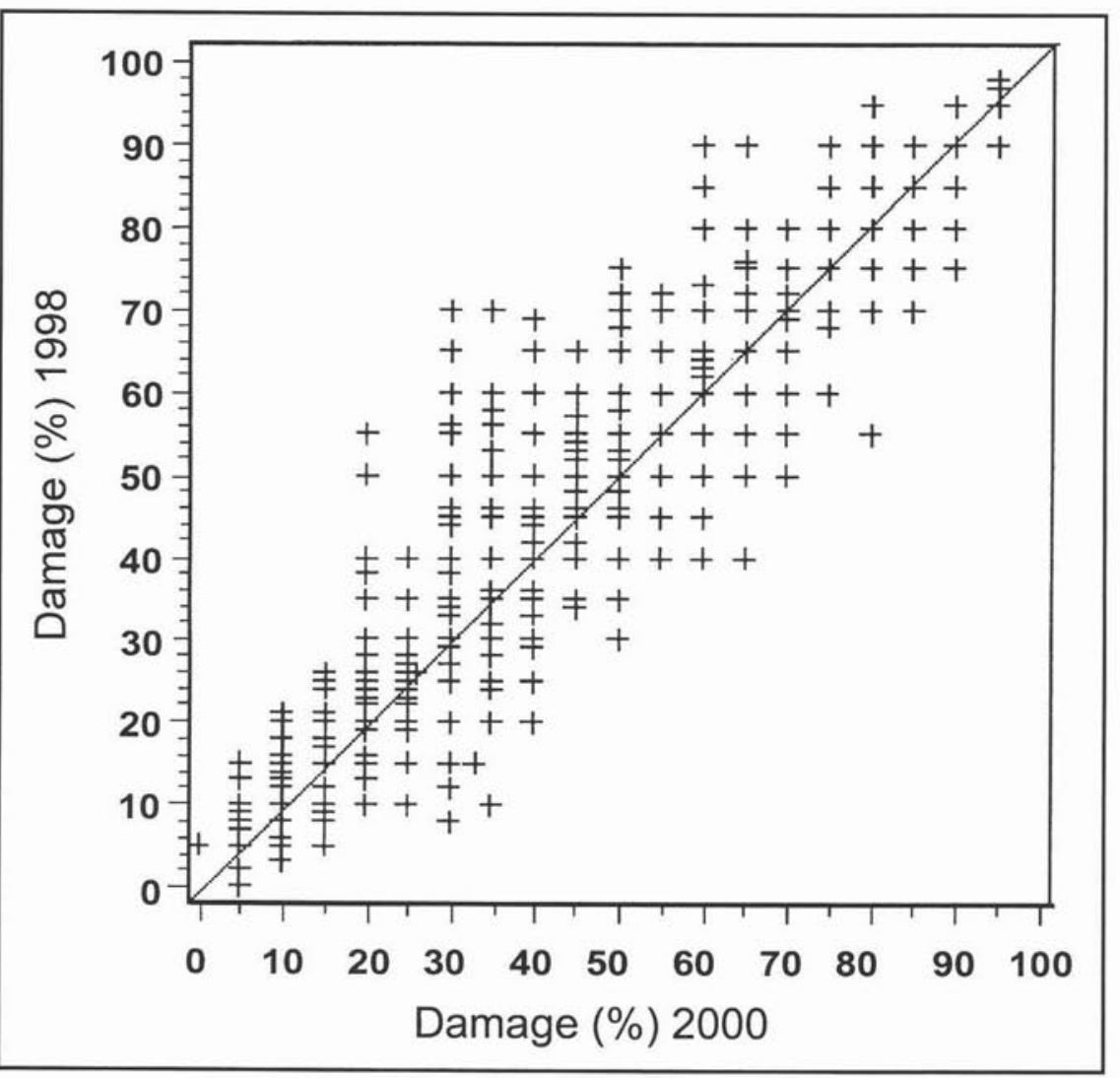

Fig. 3. Comparing visual damage estimates for individual trees between 1998 and 2000 .

tion of rough records of the time required to complete various ice damage-related study tasks and general knowledge of those actively involved in the branch counting project suggest that counting branches requires about twice as much time as estimating crown damage ( $5 \mathrm{~min}$. versus $2-3 \mathrm{~min}$./tree, respectively), once technicians reach the appropriate trees. However, it should be noted that more time is required to count branches on trees with large crowns or trees with little damage than on 


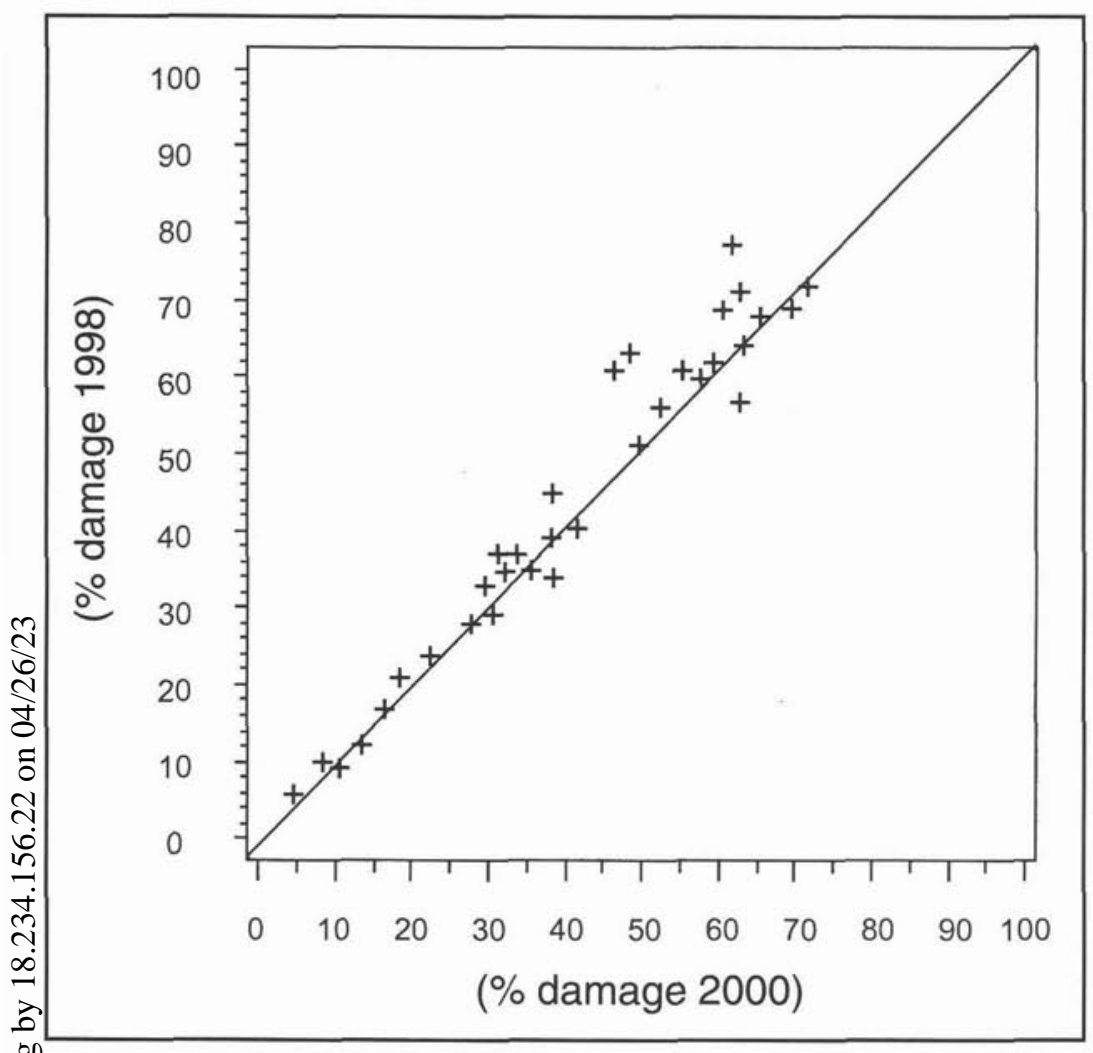

Fig. 4. Comparing averages of visual damage estimates for groups of 24 individual trees (stands) between 1998 and 2000 .

rees with small crowns or heavy damage. Those interested in Branch counting in the future will likely also want to gather damשुge estimates at the same time. However, if estimating stand Gamage is the primary goal, crown damage estimates are likely $\underset{\mathscr{E}}{\mathscr{W}}$ good choice. Because we found no relationship between \$isual estimates and branch counts, augmenting visual estimates with a few branch counts is not recommended. For example, when comparing among trees with $55 \%$ crown damage we found that one with a 53-cm DBH had nine branches, while another with a $52 \mathrm{~cm} \mathrm{DBH}$ had 21 branches.

Although some might seek both precision and accuracy in ground-based branch counting, we concentrated on precision so we could compare among trees within plots and across blocks. Greater accuracy could likely be achieved (and additional costs incurred) by acquiring more tree-based measurements (exact branch counts) of more focus trees for comparing with groundbased counts of the same trees. Nonetheless, counting branches remaining (using the methods outlined above) provides a reasonable approach to quantifying the productive capacity of damaged trees. Ter-Mikaelian and Lautenschlager (2001) found that total tree-based branch count per tree was an "excellent predictor of total leaf biomass, accounting for over $96 \%$ of leaf biomass variation."

\section{Conclusion}

Visual estimates of crown damage seem sufficient for estimating stand-level ice damage injury. Indeed, at the stand level, repeatability of crown damage estimates seems high. However, those interested in individual tree responses following ice damage or comparing damage among individual trees should consider counting branches. Indeed, this approach should also be useful in undamaged stands. However, our branch count approach has not been compared with other quantitative methods (primarily because comparable methods seem to be unavailable) or compared within or between counters or years. Therefore, it is impossible to judge the repeatability of counting branches. More research is needed to determine if branch counting or some alternative method provides the most accurate and most cost effective means to quantifying the productive capacity and related recovery potential of maple crowns after ice damage. However, we, and researchers depending on estimates of foliar biomass, believe that branch counting provides an excellent quantitative assessment of the productive capacity of damaged trees.

\section{Acknowledgements}

We thank Ken Goldsmith, Bruce Cavanaugh, Tom Lillico, John Bols, John Grady, Knox Thompson, and Jane McCann for field support in 1998; Brian Clayton, Jim Singleton, and Brian Duncan for field support in 2000; David Oliver for tree-based counts; Peter Neave and Herman Ebbers for field assistance; Geoff McVey for coordinating field work and reviewing an early draft of this paper; John Pedlar for data analysis; Cameron Lavender and David Kerr for allowing us to work in their woodlots; Trudy Vaittinen for graphics support; Michael Ter-Mikaelian for ideas throughout and his review of this paper; Cathy Nielsen, Bill Leak, Abby Obenchain, and Wendeline Price for reviewing and editing an earlier draft of this paper. Funding for this project was provided under the Canada-Ontario Agreement for the Ice Storm Economic Recovery Assistance Program, Annex A, Assistance for the Agricultural Sector and Rural Communities in Eastern Ontario. This program was jointly funded by the Government of Canada and the Government of Ontario. 


\section{References}

Boulet, B., F. Trottier and G. Roy. 2000. Management of ice damaged stands. Min. Res. Nat., Gov. du Quebec, ISBN:2-550-35993-3 (Dist. Code:2000-3070).

Irland, L.C. 1998. Ice storm 1998 and the forests of the northeast: A preliminary assessment. J. For. 96(9): 32-40.

Lautenschlager, R.A. and C. Nielsen. 1999. Ontario's forest science efforts following the 1998 ice storm. For. Chron. 75(4): 633-641.
Olthof, I., D.J. King and R.A. Lautenschlager 2001. Leaf area index change in ice-storm-damaged sugar maple stands. For. Chron. 77(4): 627-635.

Ter-Mikaelian, M. and R.A. Lautenschlager. 2001. Predictive equations for leaf area and biomass for sugar bushes in eastern Ontario. For. Chron. 77(4): 643-649.

Van Dyke, O. 1999. A literature review of ice storm impacts on forests in eastern North America. Tech. Rept. \#112, Ontario Min. Nat. Resour., Southcentral Sci. Sect., North Bay, ON. 